\title{
BIBLIOGRAFIA SOBRE HISTORIA DE LA SOCIOLOGIA A CATALUNYA I A ESPANYA
}

\author{
Xavier Marín \\ Francisco J. Miguel \\ José Antonio Noguera \\ Xavier Rambla \\ Joan Taguenca \\ Departament de Sociologia \\ Universitat Autònoma de Barcelona
}

Alsius, S. "I Simposio en Bellaterra. Conversaciones sobre la situación de la sociología en la Universidad de Barcelona», dins Papers. Revista de Sociologia, núm. 2, 1974, pp. 179-200.

Alvarez Uría, F.; Varela, J. "La galaxia sociológica. Colegios invisibles y relaciones de poder en el proceso de institucionalización de la sociología en Españan, dins Ibáñez, f.: Las Ciencias Sociales en España. Madrid, Universidad Complutense, 1992.

Aubach, M.T. Los origenes del catolicismo social en Barcelona en la segunda mitad del siglo XIX. Tesi Doctoral. Universitat de València, 1969.

Auhofer, H. La sociología de Jaime Balmes. Madrid, Rialp, 1945.

Boix Selva, E. "Sociología", dins Enciclopedia Universal Ilustrada. Madrid, Espasa-Calpe, 1962.

Carreras Artau, T. "Orígenes doctrinales de la sociología. Comte y Balmes", dins Revista Internacional de Sociologia núm. 22-23, año VI, 1948.

Castillo, J. "Apuntes para una historia de la sociología española", dins Mitchell, G.D.: Historia de la Sociologia, vol. 2, Guadarrama, 1973.

Cazorla, J. "Estudios empíricos de sociología española», dins Anales de Sociología, núm. 3, Madrid, 1969.

Comin, A. «La racionalidad de lo irracional. Notas sobre la investigación sociológica en Españan, dins Cuadernos para el diálogo, núrn. 27, octubre 1971, pp.37-40.

Conde, J. "Sociología de la sociología", dins Revista de Estudios Políticos, 1951.

Crespán, J.L. "La enseñanza de la sociología en la ciudad de Barcelona", dins Papers. Revista de Sociologia, núm. I, 1973, pp. 219-224 
"Papers": Revista de Sociologia

DD.AA. "Balmes y lo social», dins Revista Internacional de Sociologia, núm. 22-23, 1948 .

DD.AA. Sociologia española de los años setenta. Madrid, Confederación Española de Cajas de Ahorro, 1971.

DD.AA. Veinticinco años de sociologia en España. Madrid, CIS, 1988.

Del Campo, S. "La vocación de la sociología españolan dins Anales de Sociología, núm. 3, 1969 , pp. 3-6.

Díaz, E. La filosofia social del krausismo español Madrid, Edicusa, 1973.

Diez Nicolás, J. Bibliografia de sociología en lengua castellana. Granada, Universidad de Granada, 1973.

Díez Nicolás, J.; Pino, J. del; Gobernado, R. Cincuenta años de sociologia en España. Bibliografia de sociología en lengua castellana. Málaga, Universidad de Málaga, 1984.

Estruch, J.; Giner, S. "Sociologia", dins Ictineu. Diccionari de les ciències de la societat als Països Catalans. Barcelona, Edicions 62, 1979.

Estruch, J.; Cardús, S. Consideracions sobre la crisi actual de la sociologia. Separata del Butlletí de la Fundació Jaume Bofill. Barcelona, 1984

Fraga. M. Balmes, fundador de la sociologia positiva en España. Vic, Ayuntamiento de Vic, 1955.

García de León, M.A. "Sobre la sociología española” (mimeo).

Giner, S.; Moreno, L. (comps.): Sociologia en España. Madrid, CSIC, 1990.

Giner, S. «El descobriment sociologic de Catalunya: tres notes breus", dins Papers. Revista de Sociologia, núm. 12, 1979, pp.17-25.

Giner, S. "Virtudes e indigencias de la sociología española», dins Castellet, J.M.: La cultura bajo el franquismo. Barcelona, Ed. de Bolsillo, 1977.

Gómez Arboleya, E, "La sociedad moderna y los comienzos del saber socioIógicon, dins Anuario de Filosofia del Derecho, Madrid 1954.

Gómez Arboleya, E. "Sociología en España", dins Revista de Estudios Políticos, núm. 98, 1958.

Gurvitch, G.; Moore, W. Sociología del s. XX. Ed. Barcelona, Ateneo, 1965.

Hermet, Guy. "La sociología empírica en España», dins Anales de Sociología, núm. 4-5, 1968.

Ibáñez, Jesús (coord.). Las Ciencias Sociales en España. Madrid, Universidad Complutense, 1992.

Iturrate, J.L. "Sociología en España. Notas para su historia", dins La sociologia. Diccionarios del Saber Moderno. Bilbao, Mensajero, 1975.

Jerez Mir, R. La introducción de la sociologia en España. Manuel Sales i Ferré. Madrid, Ayuso, 1975.

Laporta, F.J. Adolfo Posada. Politica y sociología en la crisis del liberalismo español. Madrid, Edicusa, 1974.

Legaz Lacambra, L. "El pensamiento social de Joaquin Costa", dins Revista Internacional de Sociología, núm. 18/19, vol.V., 1947. 
Legaz Lacambra, L. "R. Madrid, de la Sagra, sociólogo español», dins Revista Internacional de Sociologia, núm. 14, 1946.

López Calvo, L. "Un análisis de la evolución temática en la producción bibliográfica de la sociología española (1940-1983)». Comunicació presentada al $I V$ Congreso Español de Sociología. Sociologia entre dos mundos. Madrid, FES, 1992 .

Marsal, J.F.; Miguel, A. de: "El raquitismo de la enseñanza de las ciencias sociales en las universidades españolas», Sistema, núm. 24-25, octubre 1973.

Marsal, J.F. "La sociología académica española después de la guerra civil», dins Teoria y crítica sociologicas. Madrid, Biblioteca Universitaria Guadiana, 1977.

Martín Granizo, L. Biografia de sociólogos españoles. Madrid, Ministerio del Trabajo, 1963.

Mercadé. F. "Barcelona y sociología; primeros contactos. Los manuales», dins Papers. Revista de Sociologia, núm. 4, pp.179-200, 1975.

Mercadé. F. "Les ciències socials a la Universitat Aurònoma de Barcelona", dins Papers. Revista de Sociologia, núm. 6, pp. 229-236, 1977.

Miguel, A. de. Sociologia o subversión. Barcelona, Plaza-Janés, 1972.

Miguel, A. de. Homo sociologicus bispanicus. Barcelona, Barral, 1973.

Miguel, A. de. "Testimonio personal sobre la sociología en un país como Españan, dins Bottomore, T.: La miseria de la sociologia. Madrid, Tecnos, 1982.

Miguel, J. de. "Para una sociología de la sociología española», dins Sociología española de los años setenta. Madrid, Confederación Española de Cajas de Ahorro, 1971.

Miguel, J. de. "Una bibliografía de los orígenes de la investigación social en España (hasta 1956)", dins Sociología española de los años setenta. Madrid, Confederación Española de Cajas de Ahorro, 1971.

Miguel, J. de; Moyer, M. G. "Sociology in Spain", dins Current Sociology, vol. 27, núm. 1, spring 1979.

Moya, C. "Sociología y libertad", dins Revista de Estudios Politicos, núm. 128, març-abril 1963.

Moya, C. Sociólogos y sociologia. Madrid, Siglo XXI, 1970.

Núnez Encabo, M. Los orígenes de la sociologia en España. Madrid, Edicusa, 1976.

Perpiñá Rodríguez, A. "La enseñanza de la sociologia y la universidad española», dins Revista Internacional de Sociologia, núm. 8, octubre-novembre 1944, pp. 35-70.

Pinilla de las Heras, E. Crisi i anticrisi de la sociologia. Barcelona, Fundació Jaume Bofill, 1987.

Posada, A. "Sociología y anarquismo", dins Revista general de legislación y jurisprudencia, núm. 84, 1894.

Rodríguez Ibáñez, J. "The Cultural Thraw in Spain", dins Telos, núm. 30, winter 1976-77. 
"Papers": Revista de Sociologia

Sastre, V.J. et al. "Las ciencias sociales en España", dins Revista de estudios sociales $y$ de sociología aplicada, núm. 24, 1976.

Sastre, V.J. Las ciencias sociales en España. Madrid, Sáez, 1971.

Sastre, V.J.; González, J. Anuario de la sociologia española. Madrid, Euramérica, 1980.

Solé, C. "La sociologia a Espanya. Estat de la qüestió", dins Perspectiva social, núm. 30, pp.5-17, 1990.

Sotelo, I. "Sobre la institucionalización de la sociología en España», dins Sistema, núm. 3, octubre 1973.

Torns, T. "Els orígens de la sociologia a Catalunya i la figura de Santiago Valentí i Camp", dins Papers. Revista de Sociologia, núm. 31, 1989.

Torns, T. Sobre los origenes de la sociologia en Cataluña. Las aportaciones de los anarquistas (1864-1910). Tesi doctoral. Bilbao, Universidad de Detssto, 1986.

Torres Albero, C. "La comunidad de sociólogos en Madrid». Comunicació presentada al $I V$ Congreso Español de Sociología. Sociologia entre dos mundos. Madrid, FES, 1992.

\section{REVSTES DE SOCIOLOGLA A CATALUNYA I A ESPANYA*}

Aïnes

Alfoz

Anales de Sociología

Anuario de Sociología y Psicologia Jurídicas

Anuario Internacional CIDOB

Anuario Social de España

Arbor

Boletín de Ciencia Jurídica

Bolexin de Documentación del Fondo para la Investigación Económica y Social de la Confederación Española de Cajas de Ahorros

Boletín de Sociología de la Empresa

Ciencia y Razón

Comentario sociológico

Crónica de información social. Boletín interno
Cuadernos de acción social

Cuadernos de Estudios Sociales del Valle de los Cafdos/ Revista de Estudios Sociales

Cuadernos de información económica y sociologica

Cuadernos de la Gaya Ciencia

Cuadernos de Realidades Sociales

Cuadernos del Ruedo Ibérico

Cuadernos para el Diálogo

Cuenta y razón

Debats

Documentación social

Educación y Sociedad

El Basilisco

El Cárabo

El Proyecto

* Incloem també en aquesta llista algunes revistes el contingut de les quals no és estrictament socioldgic, perd que poden ser d'interès per estudiar la hisròria de la sociologia i de les ciències socials a Caralunya i a Espanya. 
El Viejo Topo

Estudios de historia social

Full informatiu de la comissió gestora de la projectada Associació Catalana de Sociologia

Gerontología y Sociedad

Informes FOESSA

Inguruak

Iniciativa i Treball. Publicació quinzenal d'informació política

La Lletra [A]. Revista llibertària

Materiales

Mientras Tanto

Migraciones 89

Negaciones

Nous Horitzons

Papers. IEMB

Papers. Revista de Sociologia

Perspectiva Social

Politica y Sociedad

Promos

Quadern d'Orientació Familiar Quadern de l'Obra Social

Quaderns d'Alliberament
Radar Social

Revista Católica de Cuestiones Sociales Revista de Ciencias Sociales de la Diputación de Barcelona

Revista de Economía y Sociología del Trabajo

Revista de Educación

Revista de Estudios Políticos

Revista de Fomento Social

Revista de Occidente

Revista de Opinión Pública/ Revista Española de Investigaciones Sociológicas

Revista de Servicio Social

Revista de Trabajo

Revista Española de Sociologia

Revista Internacional de Sociologfa

Revista mensual/ Monthly Review

Sistema

Sociologia

Sociologia del Trabajo

Telos

Teorema

Teoría y Práctica

Treballs de Sociolingǘstica Catalana

Zona Abierta/ En Teoría 